\title{
Shrinking Projection Method of Fixed Point Problems for Asymptotically Pseudocontractive Mapping in the Intermediate Sense and Mixed Equilibrium Problems in Hilbert Spaces
}

\author{
Pattanapong Tianchai \\ Faculty of Science, Maejo University, Chiangmai 50290, Thailand \\ Correspondence should be addressed to Pattanapong Tianchai, pattana@mju.ac.th \\ Received 16 June 2011; Accepted 8 September 2011 \\ Academic Editor: Yansheng Liu
}

Copyright (C) 2012 Pattanapong Tianchai. This is an open access article distributed under the Creative Commons Attribution License, which permits unrestricted use, distribution, and reproduction in any medium, provided the original work is properly cited.

This paper is concerned with a common element of the set of fixed point for an asymptotically pseudocontractive mapping in the intermediate sense and the set of solutions of the mixed equilibrium problems in Hilbert spaces. The strong convergence theorem for the above two sets is obtained by a general iterative scheme based on the shrinking projection method, which extends and improves that of Qin et al. (2010) and many others.

\section{Introduction}

Throughout this paper, we always assume that $C$ be a nonempty closed convex subset of a real Hilbert space $H$ with inner product and norm denoted by $\langle\cdot, \cdot\rangle$ and $\|\cdot\|$, respectively. For a sequence $\left\{x_{n}\right\}$ in $H$, we denote the strong convergence and the weak convergence of $\left\{x_{n}\right\}$ to $x \in H$ by $x_{n} \rightarrow x$ and $x_{n} \rightarrow x$, respectively. The domain of the function $\varphi: C \rightarrow \mathbb{R} \cup\{+\infty\}$ is the set

$$
\operatorname{dom} \varphi=\{x \in C: \varphi(x)<+\infty\}
$$

Let $\varphi: C \rightarrow \mathbb{R} \cup\{+\infty\}$ be a proper extended real-valued function, and let $\Phi$ be a bifunction from $C \times C$ into $\mathbb{R}$ such that $C \cap \operatorname{dom} \varphi \neq \emptyset$, where $\mathbb{R}$ is the set of real numbers. The so-called the mixed equilibrium problem is to find $x \in C$ such that

$$
\Phi(x, y)+\varphi(y)-\varphi(x) \geq 0, \quad \forall y \in C
$$


The set of solution of problem (1.2) is denoted by $\operatorname{MEP}(\Phi, \varphi)$, that is,

$$
\operatorname{MEP}(\Phi, \varphi)=\{x \in C: \Phi(x, y)+\varphi(y)-\varphi(x) \geq 0, \forall y \in C\}
$$

It is obvious that if $x$ is a solution of problem (1.2) then $x \in \operatorname{dom} \varphi$. As special cases of problem (1.2), we have the following.

(i) If $\varphi=0$, then problem (1.2) is reduced to find $x \in C$ such that

$$
\Phi(x, y) \geq 0, \quad \forall y \in C
$$

We denote by $\mathrm{EP}(\Phi)$ the set of solutions of equilibrium problem, which problem (1.4) was studied by Blum and Oettli [1].

(ii) If $\Phi(x, y)=\langle B x, y-x\rangle$ for all $x, y \in C$ where a mapping $B: C \rightarrow H$, then problem (1.4) is reduced to find $x \in C$ such that

$$
\langle B x, y-x\rangle \geq 0, \quad \forall y \in C
$$

We denote by $\operatorname{VI}(C, B)$ the set of solutions of variational inequality problem, which problem (1.5) was studied by Hartman and Stampacchia [2].

(iii) If $\Phi=0$, then problem (1.2) is reduced to find $x \in C$ such that

$$
\varphi(y)-\varphi(x) \geq 0, \quad \forall y \in C
$$

We denote by $\operatorname{Argmin}(\varphi)$ the set of solutions of minimize problem.

Recall that $P_{C}$ is the metric projection of $H$ onto $C$; that is, for each $x \in H$ there exists the unique point in $P_{C} x \in C$ such that $\left\|x-P_{C} x\right\|=\min _{y \in C}\|x-y\|$. A mapping $T: C \rightarrow C$ is called nonexpansive if $\|T x-T y\| \leq\|x-y\|$ for all $x, y \in C$, and uniformly L-Lipschitzian if there exists a constant $L>0$ such that for each $n \in \mathbb{N},\left\|T^{n} x-T^{n} y\right\| \leq L\|x-y\|$ for all $x, y \in C$, and a mapping $f: C \rightarrow C$ is called a contraction if there exists a constant $\alpha \in(0,1)$ such that $\|f(x)-f(y)\| \leq \alpha\|x-y\|$ for all $x, y \in C$. A point $x \in C$ is a fixed point of $T$ provided $T x=x$. We denote by $F(T)$ the set of fixed points of $T$; that is, $F(T)=\{x \in C: T x=x\}$. If $C$ is a nonempty bounded closed convex subset of $H$ and $T$ is a nonexpansive mapping of $C$ into itself, then $F(T)$ is nonempty (see [3]).

Iterative methods are often used to solve the fixed point equation $T x=x$. The most well-known method is perhaps the Picard successive iteration method when $T$ is a contraction. Picard's method generates a sequence $\left\{x_{n}\right\}$ successively as $x_{n+1}=T x_{n}$ for all $n \in \mathbb{N}$ with $x_{1}=x$ chosen arbitrarily, and this sequence converges in norm to the unique fixed point of $T$. However, if $T$ is not a contraction (for instance, if $T$ is a nonexpansive), then Picard's successive iteration fails, in general, to converge. Instead, Mann's iteration method for a nonexpansive mapping $T$ (see [4]) prevails, generates a sequence $\left\{x_{n}\right\}$ recursively by

$$
x_{n+1}=\alpha_{n} x_{n}+\left(1-\alpha_{n}\right) T x_{n}, \quad \forall n \in \mathbb{N},
$$

where $x_{1}=x \in C$ chosen arbitrarily and the sequence $\left\{\alpha_{n}\right\}$ lies in the interval $[0,1]$. Recall that a mapping $T: C \rightarrow C$ is said to be 
(i) asymptotically pseudocontractive $[5,6]$ if there exists a sequence $k_{n} \subset[1, \infty)$ with $\lim _{n \rightarrow \infty} k_{n}=1$ such that

$$
\left\langle T^{n} x-T^{n} y, x-y\right\rangle \leq k_{n}\|x-y\|^{2}, \quad \forall x, y \in C, \forall n \in \mathbb{N}
$$

it is easy to see that (1.8) is equivalent to

$$
\left\|T^{n} x-T^{n} y\right\|^{2} \leq\left(2 k_{n}-1\right)\|x-y\|^{2}+\left\|\left(I-T^{n}\right) x-\left(I-T^{n}\right) y\right\|^{2}, \quad \forall x, y \in C,
$$

for all $n \in \mathbb{N}$,

(ii) asymptotically pseudocontractive in the intermediate sense [7] if there exists a sequence $k_{n} \subset[1, \infty)$ with $\lim _{n \rightarrow \infty} k_{n}=1$ such that

$$
\limsup _{n \rightarrow \infty} \sup _{x, y \in C}\left(\left\langle T^{n} x-T^{n} y, x-y\right\rangle-k_{n}\|x-y\|^{2}\right) \leq 0
$$

if we define

$$
\tau_{n}=\max \left\{0, \sup _{x, y \in C}\left(\left\langle T^{n} x-T^{n} y, x-y\right\rangle-k_{n}\|x-y\|^{2}\right)\right\}
$$

then $\lim _{n \rightarrow \infty} \tau_{n}=0$ and it follows that (1.10) is reduced to

$$
\left\langle T^{n} x-T^{n} y, x-y\right\rangle \leq k_{n}\|x-y\|^{2}+\tau_{n}, \quad \forall x, y \in C, \forall n \in \mathbb{N}
$$

it is easy to see that (1.12) is equivalent to

$$
\left\|T^{n} x-T^{n} y\right\|^{2} \leq\left(2 k_{n}-1\right)\|x-y\|^{2}+\left\|\left(I-T^{n}\right) x-\left(I-T^{n}\right) y\right\|^{2}+2 \tau_{n}, \quad \forall x, y \in C,
$$

for all $n \in \mathbb{N}$; it is obvious that if $\tau_{n}=0$ for all $n \in \mathbb{N}$, then the class of asymptotically pseudocontractive mappings in the intermediate sense is reduced to the class of asymptotically pseudocontractive mappings.

The Mann's algorithm for nonexpansive mappings has been extensively investigated (see [8-10] and the references therein). One of the well-known results is proven by Reich [10] for a nonexpansive mapping $T$ on $C$, which asserts the weak convergence of the sequence $\left\{x_{n}\right\}$ generated by (1.7) in a uniformly convex Banach space with a Frechet differentiable norm under the control condition $\sum_{n=1}^{\infty} \alpha_{n}\left(1-\alpha_{n}\right)=\infty$. It is known that the Mann's iteration (1.7) is in general not strongly convergent (see [11]). The strong convergence guaranteed has been proposed by Nakajo and Takahashi [12], they modified the Mann's iteration method (1.7) which is to find a fixed point of a nonexpansive mapping by a hybrid method, which called that the shrinking projection method (or the CQ method) as the following theorem. 
Theorem NT. Let $C$ be a nonempty closed convex subset of a real Hilbert space $H$. Let $T$ be a nonexpansive mapping of $C$ into itself such that $F(T) \neq \emptyset$. Suppose that $x_{1}=x \in C$ chosen arbitrarily and $\left\{x_{n}\right\}$ the sequence defined by

$$
\begin{aligned}
y_{n} & =\alpha_{n} x_{n}+\left(1-\alpha_{n}\right) T x_{n}, \\
C_{n} & =\left\{z \in C:\left\|y_{n}-z\right\| \leq\left\|x_{n}-z\right\|\right\}, \\
Q_{n} & =\left\{z \in C:\left\langle x_{n}-z, x_{1}-x_{n}\right\rangle \geq 0\right\}, \\
x_{n+1} & =P_{C_{n} \cap Q_{n}}\left(x_{1}\right), \quad \forall n \in \mathbb{N},
\end{aligned}
$$

where $0 \leq \alpha_{n} \leq \alpha<1$. Then $\left\{x_{n}\right\}$ converges strongly to $P_{F(T)}\left(x_{1}\right)$.

Subsequently, Schu [5] modified Ishikawa's iteration method (see [13]) for the class of asymptotically pseudocontractive mappings as the following theorem.

Theorem S. Let $C$ be a nonempty bounded closed convex subset of a real Hilbert space $H$. Let $T: C \rightarrow C$ be a completely continuous uniformly L-Lipschitzian such that $L>0$ and asymptotically pseudocontractive mapping defined as in (1.9) with the sequence $\left\{k_{n}\right\} \subset[1, \infty)$ such that $\lim _{n \rightarrow \infty} k_{n}=1$. Let $q_{n}=2 k_{n}-1$ for all $n \in \mathbb{N}$. Suppose that $x_{1}=x \in C$ chosen arbitrarily and $\left\{x_{n}\right\}$ the sequence defined by

$$
\begin{aligned}
y_{n} & =\beta_{n} T^{n} x_{n}+\left(1-\beta_{n}\right) x_{n}, \\
x_{n+1} & =\alpha_{n} T^{n} y_{n}+\left(1-\alpha_{n}\right) x_{n}, \quad \forall n \in \mathbb{N},
\end{aligned}
$$

where $\left\{\alpha_{n}\right\},\left\{\beta_{n}\right\} \subset(0,1)$ such that $\epsilon \leq \alpha_{n} \leq \beta_{n} \leq b$ for some $\epsilon>0$ and $b \in\left(0, L^{-2}\left(\sqrt{1+L^{2}}-1\right)\right)$ and $\sum_{n=1}^{\infty}\left(q_{n}^{2}-1\right)<\infty$. Then $\left\{x_{n}\right\}$ converges strongly to some fixed point of $T$.

Quite recently, Zhou [14] showed that every uniformly L-Lipschitzian and asymptotically pseudocontractions which are also uniformly asymptotically regular has a fixed point and the fixed point set is closed and convex, and he also introduced iterative scheme to find a fixed point of a uniformly $L$-Lipschitzian and asymptotically pseudocontractive mapping as the following theorem.

Theorem Z. Let $C$ be a nonempty bounded closed convex subset of a real Hilbert space $H$. Let $T$ : $C \rightarrow C$ be a uniformly L-Lipschitzian such that $L>0$ and asymptotically pseudocontractive mapping with a fixed point defined as in (1.8) with the sequence $\left\{k_{n}\right\} \subset[1, \infty)$ such that $\lim _{n \rightarrow \infty} k_{n}=1$. Suppose that $x_{1}=x \in C$ chosen arbitrarily and $\left\{x_{n}\right\}$ the sequence defined by

$$
\begin{aligned}
y_{n}= & \left(1-\alpha_{n}\right) x_{n}+\alpha_{n} T^{n} x_{n}, \\
C_{n}=\{ & z \in C: \alpha_{n}\left(1-(1+L) \alpha_{n}\right)\left\|x_{n}-T^{n} x_{n}\right\|^{2} \leq\left\langle x_{n}-z, y_{n}-T^{n} y_{n}\right\rangle \\
& \left.+\left(k_{n}-1\right)(\operatorname{diam} C)^{2}\right\},
\end{aligned}
$$




$$
\begin{aligned}
Q_{n} & =\left\{z \in C:\left\langle x_{n}-z, x_{1}-x_{n}\right\rangle \geq 0\right\}, \\
x_{n+1} & =P_{C_{n} \cap Q_{n}}\left(x_{1}\right), \quad \forall n \in \mathbb{N},
\end{aligned}
$$

where $\left\{\alpha_{n}\right\} \subset[a, b]$ such that $0<a<b<1 /(1+L)$. Then $\left\{x_{n}\right\}$ converges strongly to $P_{F(T)}\left(x_{1}\right)$.

To be more precisely, Qin et al. [7] showed in the framework of a real Hilbert spaces $H$ for the uniformly $L$-Lipschitzian and asymptotically pseudocontractive mapping in the intermediate sense that the fixed point set is closed and convex (see Lemma 1.4 in [7]) and the demiclosedness principle holds (see Lemma 1.5 in [7]), and they also introduced an iterative scheme to find a fixed point of a uniformly $L$-Lipschitzian such that $L>0$ and asymptotically pseudocontractive mapping in the intermediate sense on a nonempty bounded closed convex $C \subset H$ defined as in (1.13) with the sequences $\left\{k_{n}\right\} \subset[1, \infty)$ and $\left\{\tau_{n}\right\} \subset[0, \infty)$ such that $\lim _{n \rightarrow \infty} k_{n}=1$ and $\lim _{n \rightarrow \infty} \tau_{n}=0$, and let $q_{n}=2 k_{n}-1$ for all $n \in \mathbb{N}$ as follows:

$$
\begin{aligned}
x_{1}= & x \in C \text { chosen arbitrarily, } \\
z_{n}= & \left(1-\beta_{n}\right) x_{n}+\beta_{n} T^{n} x_{n}, \\
y_{n}= & \left(1-\alpha_{n}\right) x_{n}+\alpha_{n} T^{n} z_{n}, \\
C_{n}=\{ & z \in C:\left\|y_{n}-z\right\|^{2} \leq\left\|x_{n}-z\right\|^{2}+\alpha_{n} \theta_{n} \\
& \left.\quad+\alpha_{n} \beta_{\mathrm{n}}\left(\beta_{n} q_{n}+\beta_{n}^{2} L^{2}+\beta_{n}-1\right)\left\|T^{n} x_{n}-x_{n}\right\|^{2}\right\}, \\
Q_{n}= & \left\{z \in C:\left\langle x_{n}-z, x_{1}-x_{n}\right\rangle \geq 0\right\}, \\
x_{n+1}= & P_{C_{n} \cap Q_{n}}\left(x_{1}\right), \quad \forall n \in \mathbb{N},
\end{aligned}
$$

where $\theta_{n}=\left(q_{n}\left[1+\beta_{n}\left(q_{n}-1\right)\right]-1\right) \cdot(\operatorname{diam} C)^{2}+2\left(\beta_{n} q_{n}+1\right) \tau_{n}<\infty$. They proved that under the sequences $\left\{\alpha_{n}\right\},\left\{\beta_{n}\right\} \subset(0,1)$ such that $a \leq \alpha_{n} \leq \beta_{n} \leq b$ for some $a>0$ and $b \in\left(0, L^{-2}\left(\sqrt{1+L^{2}}-\right.\right.$ $1)$ ), if $F(T)$ is nonempty, then the sequence $\left\{x_{n}\right\}$ generated by (1.17) converges strongly to a fixed point of $T$.

Inspired and motivated by the works mentioned above, in this paper, we introduce a general iterative scheme (3.1) below to find a common element of the set of fixed point for an asymptotically pseudocontractive mapping in the intermediate sense and the set of solutions of mixed equilibrium problems in Hilbert spaces. The strong convergence theorem for the above two sets is obtained by a general iterative scheme based on the shrinking projection method which extends and improves Qin et al. [7] and many others.

\section{Preliminaries}

Let $C$ be a nonempty closed convex subset of a real Hilbert space $H$. For solving the mixed equilibrium problem, let us assume that the bifunction $\Phi: C \times C \rightarrow \mathbb{R}$, the function $\varphi: C \rightarrow$ $\mathbb{R} \cup\{+\infty\}$ and the set $C$ satisfy the following conditions:

(A1) $\Phi(x, x)=0$ for all $x \in C$; 
(A2) $\Phi$ is monotone; that is, $\Phi(x, y)+\Phi(y, x) \leq 0$ for all $x, y \in C$;

(A3) for each $x, y, z \in C$,

$$
\lim _{t \downarrow 0} \Phi(t z+(1-t) x, y) \leq \Phi(x, y)
$$

(A4) for each $x \in C, y \mapsto \Phi(x, y)$ is convex and lower semicontinuous;

(A5) for each $y \in C, x \mapsto \Phi(x, y)$ is weakly upper semicontinuous;

(B1) for each $x \in C$ and $r>0$, there exists a bounded subset $D_{x} \subset C$ and $y_{x} \in C$ such that for any $z \in C \backslash D_{x}$,

$$
\Phi\left(z, y_{x}\right)+\varphi\left(y_{x}\right)-\varphi(z)+\frac{1}{r}\left\langle y_{x}-z, z-x\right\rangle<0 ;
$$

(B2) $C$ is a bounded set.

Lemma 2.1 (see [15]). Let $H$ be a Hilbert space. For any $x, y \in H$ and $\lambda \in \mathbb{R}$, we have

$$
\|\lambda x+(1-\lambda) y\|^{2}=\lambda\|x\|^{2}+(1-\lambda)\|y\|^{2}-\lambda(1-\lambda)\|x-y\|^{2} .
$$

Lemma 2.2 (see [3]). Let $C$ be a nonempty closed convex subset of a Hilbert space $H$. Then the following inequality holds:

$$
\left\langle x-P_{C} x, P_{C} x-y\right\rangle \geq 0, \quad \forall x \in H, y \in C .
$$

Lemma 2.3 (see [16]). Let $C$ be a nonempty closed convex subset of a Hilbert space $H, \Phi: C \times C \rightarrow$ $\mathbb{R}$ satisfying the conditions (A1)-(A5), and let $\varphi: C \rightarrow \mathbb{R} \cup\{+\infty\}$ be a proper lower semicontinuous and convex function. Assume that either (B1) or (B2) holds. For $r>0$, define a mapping $S_{r}: C \rightarrow C$ as follows:

$$
S_{r}(x)=\left\{z \in C: \Phi(z, y)+\varphi(y)-\varphi(z)+\frac{1}{r}\langle y-z, z-x\rangle \geq 0, \forall y \in C\right\}
$$

for all $x \in C$. Then, the following statement hold:

(1) for each $x \in C, S_{r}(x) \neq \emptyset$;

(2) $S_{r}$ is single-valued;

(3) $S_{r}$ is firmly nonexpansive; that is, for any $x, y \in C$,

$$
\left\|S_{r} x-S_{r} y\right\|^{2} \leq\left\langle S_{r} x-S_{r} y, x-y\right\rangle ;
$$

(4) $F\left(S_{r}\right)=\operatorname{MEP}(\Phi, \varphi)$;

(5) $\operatorname{MEP}(\Phi, \varphi)$ is closed and convex. 
Lemma 2.4 (see [3]). Every Hilbert space H has Radon-Riesz property or Kadec-Klee property, that is, for a sequence $\left\{x_{n}\right\} \subset H$ with $x_{n} \rightarrow x$ and $\left\|x_{n}\right\| \rightarrow\|x\|$ then $x_{n} \rightarrow x$.

Lemma 2.5 (see [7]). Let $C$ be a nonempty closed convex of a real Hilbert space $H$, and let $T: C \rightarrow$ $C$ be a uniformly L-Lipschitz and asymptotically pseudocontractive mapping in the intermediate sense such that $F(T)$ is nonempty. Then $I-T$ is demiclosed at zero. That is, whenever $\left\{x_{n}\right\}$ is a sequence in $C$ weakly converging to some $x \in C$ and the sequence $\left\{(I-T) x_{n}\right\}$ strongly converges to some $y$, it follows that $(I-T) x=y$.

\section{Main Results}

Theorem 3.1. Let $C$ be a nonempty closed convex subset of a real Hilbert space $H, \Phi$ a bifunction from $C \times C$ into $\mathbb{R}$ satisfying the conditions (A1)-(A5), and $\varphi: C \rightarrow \mathbb{R} \cup\{+\infty\}$ a proper lower semicontinuous and convex function with either (B1) or (B2) holds. Let $T: C \rightarrow C$ be a uniformly $L$ -Lipschitzian such that $L>0$ and asymptotically pseudocontractive mapping in the intermediate sense defined as in (1.13) with the sequences $\left\{k_{n}\right\} \subset[1, \infty)$ and $\left\{\tau_{n}\right\} \subset[0, \infty)$ such that $\lim _{n \rightarrow \infty} k_{n}=1$ and $\lim _{n \rightarrow \infty} \tau_{n}=0$. Let $q_{n}=2 k_{n}-1$ for all $n \in \mathbb{N}$. Assume that $\Omega:=F(T) \cap \operatorname{MEP}(\Phi, \varphi)$ be a nonempty bounded subset of $C$. For $x_{1}=x \in C$ chosen arbitrarily, suppose that $\left\{x_{n}\right\},\left\{y_{n}\right\},\left\{z_{n}\right\}$, and $\left\{u_{n}\right\}$ are generated iteratively by

$$
\begin{gathered}
u_{n} \in C \text { such that } \\
\Phi\left(u_{n}, y\right)+\varphi(y)-\varphi\left(u_{n}\right)+\frac{1}{r_{n}}\left\langle y-u_{n}, u_{n}-x_{n}\right\rangle \geq 0, \quad \forall y \in C, \\
z_{n}=\left(1-\beta_{n}\right) u_{n}+\beta_{n} T^{n} u_{n}, \\
y_{n}=\left(1-\alpha_{n}\right) u_{n}+\alpha_{n} T^{n} z_{n}, \\
C_{n+1}=\left\{z \in C_{n} \cap Q_{n}:\left\|y_{n}-z\right\|^{2} \leq\left\|x_{n}-z\right\|^{2}+\alpha_{n} \theta_{n}\right. \\
\left.+\alpha_{n} \beta_{n}\left(\beta_{n} q_{n}+\beta_{n}^{2} L^{2}+\beta_{n}-1\right)\left\|T^{n} u_{n}-u_{n}\right\|^{2}\right\}, \\
Q_{n+1}=\left\{z \in C_{n} \cap Q_{n}:\left\langle x_{n}-z, x_{1}-x_{n}\right\rangle \geq 0\right\}, \\
C_{1}=Q_{1}=C, \\
x_{n+1}=P_{C_{n+1} \cap Q_{n+1}}\left(x_{1}\right), \quad \forall n \in \mathbb{N},
\end{gathered}
$$

where $\theta_{n}=\left(q_{n}\left[1+\beta_{n}\left(q_{n}-1\right)\right]-1\right) \cdot \Delta_{n}^{2}+2\left(\beta_{n} q_{n}+1\right) \tau_{n}$ and $\Delta_{n}=\sup \left\{\left\|x_{n}-z\right\|: z \in \Omega\right\}<\infty$ satisfying the following conditions:

(C1) $\left\{\alpha_{n}\right\},\left\{\beta_{n}\right\} \subset(0,1)$ such that $a \leq \alpha_{n} \leq \beta_{n} \leq b$ for some $a>0$ and $b \in\left(0, L^{-2}\left(\sqrt{1+L^{2}}-\right.\right.$ $1))$;

(C2) $\left\{r_{n}\right\} \subset[r, \infty)$ for some $r>0$;

(C3) $\sum_{n=1}^{\infty}\left|r_{n+1}-r_{n}\right|<\infty$.

Then the sequences $\left\{x_{n}\right\},\left\{y_{n}\right\},\left\{z_{n}\right\}$, and $\left\{u_{n}\right\}$ converge strongly to $w=P_{\Omega}\left(x_{1}\right)$. 
Proof. Pick $p \in \Omega$. Therefore, by (3.1) and the definition of $S_{r_{n}}$ in Lemma 2.3, we have

$$
u_{n}=S_{r_{n}} x_{n} \in \operatorname{dom} \varphi,
$$

and by $T p=p$, and Lemma 2.3 (4), we have

$$
T^{n} p=p=S_{r_{n}} p
$$

By (3.2), (3.3), and the nonexpansiveness of $S_{r_{n}}$, we have

$$
\left\|u_{n}-p\right\|=\left\|S_{r_{n}} x_{n}-S_{r_{n}} p\right\| \leq\left\|x_{n}-p\right\| .
$$

By (3.3), Lemma 2.1, the uniformly $L$-Lipschitzian of $T$, and the asymptotically pseudocontractive mapping in the intermediate sense of $T$, we have

$$
\begin{aligned}
\left\|y_{n}-p\right\|^{2}= & \left\|\left(1-\alpha_{n}\right)\left(u_{n}-p\right)+\alpha_{n}\left(T^{n} z_{n}-p\right)\right\|^{2} \\
= & \left(1-\alpha_{n}\right)\left\|u_{n}-p\right\|^{2}+\alpha_{n}\left\|T^{n} z_{n}-p\right\|^{2}-\alpha_{n}\left(1-\alpha_{n}\right)\left\|T^{n} z_{n}-u_{n}\right\|^{2} \\
\leq & \left(1-\alpha_{n}\right)\left\|u_{n}-p\right\|^{2}+\alpha_{n}\left(q_{n}\left\|z_{n}-p\right\|^{2}+\left\|z_{n}-T^{n} z_{n}\right\|^{2}+2 \tau_{n}\right) \\
& -\alpha_{n}\left(1-\alpha_{n}\right)\left\|T^{n} z_{n}-u_{n}\right\|^{2}, \\
\left\|z_{n}-T^{n} z_{n}\right\|^{2}= & \left\|\left(1-\beta_{n}\right)\left(u_{n}-T^{n} z_{n}\right)+\beta_{n}\left(T^{n} u_{n}-T^{n} z_{n}\right)\right\|^{2} \\
= & \left(1-\beta_{n}\right)\left\|u_{n}-T^{n} z_{n}\right\|^{2}+\beta_{n}\left\|T^{n} u_{n}-T^{n} z_{n}\right\|^{2} \\
& -\beta_{n}\left(1-\beta_{n}\right)\left\|T^{n} u_{n}-u_{n}\right\|^{2} \\
\leq & \left(1-\beta_{n}\right)\left\|u_{n}-T^{n} z_{n}\right\|^{2}+\beta_{n} L^{2}\left\|u_{n}-z_{n}\right\|^{2} \\
& -\beta_{n}\left(1-\beta_{n}\right)\left\|T^{n} u_{n}-u_{n}\right\|^{2} \\
= & \left(1-\beta_{n}\right)\left\|u_{n}-T^{n} z_{n}\right\|^{2} \\
& +\beta_{n}\left(\beta_{n}^{2} L^{2}+\beta_{n}-1\right)\left\|T^{n} u_{n}-u_{n}\right\|^{2}, \\
= & \left\|\left(1-\beta_{n}\right)\left(u_{n}-p\right)+\beta_{n}\left(T^{n} u_{n}-p\right)\right\|^{2} \\
= & \left(1-\beta_{n}\right)\left\|u_{n}-p\right\|^{2}+\beta_{n}\left\|T^{n} u_{n}-p\right\|^{2}-\beta_{n}\left(1-\beta_{n}\right)\left\|T^{n} u_{n}-u_{n}\right\|^{2} \\
\leq & \left(1-\beta_{n}\right)\left\|u_{n}-p\right\|^{2}+\beta_{n}\left(q_{n}\left\|u_{n}-p\right\|^{2}+\left\|u_{n}-T^{n} u_{n}\right\|^{2}+2 \tau_{n}\right) \\
& -\beta_{n}\left(1-\beta_{n}\right)\left\|T^{n} u_{n}-u_{n}\right\|^{2} \\
= & {\left[1+\beta_{n}\left(q_{n}-1\right)\right]\left\|u_{n}-p\right\|^{2}+\beta_{n}^{2}\left\|T^{n} u_{n}-u_{n}\right\|^{2}+2 \beta_{n} \tau_{n} . } \\
\left\|z_{n}-p\right\|^{2} &
\end{aligned}
$$


Substituting (3.6) and (3.7) into (3.5), and by the condition (C1) and (3.4), we have

$$
\begin{aligned}
\left\|y_{n}-p\right\|^{2} \leq & \left\|u_{n}-p\right\|^{2}+\alpha_{n}\left(q_{n}\left[1+\beta_{n}\left(q_{n}-1\right)\right]-1\right)\left\|u_{n}-p\right\|^{2} \\
& +2 \alpha_{n}\left(\beta_{n} q_{n}+1\right) \tau_{n}+\alpha_{n} \beta_{n}\left(\beta_{n} q_{n}+\beta_{n}^{2} L^{2}+\beta_{n}-1\right)\left\|T^{n} u_{n}-u_{n}\right\|^{2} \\
& -\alpha_{n}\left(\beta_{n}-\alpha_{n}\right)\left\|u_{n}-T^{n} z_{n}\right\|^{2} \\
\leq & \left\|u_{n}-p\right\|^{2}+\alpha_{n}\left(\left(q_{n}\left[1+\beta_{n}\left(q_{n}-1\right)\right]-1\right)\left\|u_{n}-p\right\|^{2}\right. \\
\quad & \left.+2\left(\beta_{n} q_{n}+1\right) \tau_{n}\right)+\alpha_{n} \beta_{n}\left(\beta_{n} q_{n}+\beta_{n}^{2} L^{2}+\beta_{n}-1\right)\left\|T^{n} u_{n}-u_{n}\right\|^{2} \\
\leq & \left\|u_{n}-p\right\|^{2}+\alpha_{n} \theta_{n} \\
& +\alpha_{n} \beta_{n}\left(\beta_{n} q_{n}+\beta_{n}^{2} L^{2}+\beta_{n}-1\right)\left\|T^{n} u_{n}-u_{n}\right\|^{2} \\
\leq & \left\|x_{n}-p\right\|^{2}+\alpha_{n} \theta_{n} \\
& +\alpha_{n} \beta_{n}\left(\beta_{n} q_{n}+\beta_{n}^{2} L^{2}+\beta_{n}-1\right)\left\|T^{n} u_{n}-u_{n}\right\|^{2},
\end{aligned}
$$

where $\theta_{n}:=\left(q_{n}\left[1+\beta_{n}\left(q_{n}-1\right)\right]-1\right) \cdot \Delta_{n}^{2}+2\left(\beta_{n} q_{n}+1\right) \tau_{n}$ and $\Delta_{n}:=\sup \left\{\left\|x_{n}-z\right\|: z \in \Omega\right\}$.

Firstly, we prove that $C_{n} \cap Q_{n}$ is closed and convex for all $n \in \mathbb{N}$. It is obvious that $C_{1} \cap Q_{1}$ is closed, and by mathematical induction that $C_{n} \cap Q_{n}$ is closed for all $n \geq 2$, that is $C_{n} \cap Q_{n}$ is closed for all $n \in \mathbb{N}$. Let $\epsilon_{n}=\alpha_{n} \theta_{n}+\alpha_{n} \beta_{n}\left(\beta_{n} q_{n}+\beta_{n}^{2} L^{2}+\beta_{n}-1\right)\left\|T^{n} u_{n}-u_{n}\right\|^{2}$. Since for any $z \in C,\left\|y_{n}-z\right\|^{2} \leq\left\|x_{n}-z\right\|^{2}+\epsilon_{n}$ is equivalent to

$$
\left\|y_{n}-x_{n}\right\|^{2}+2\left\langle y_{n}-x_{n}, x_{n}-z\right\rangle-\epsilon_{n} \leq 0
$$

for all $n \in \mathbb{N}$. Therefore, for any $z_{1}, z_{2} \in C_{n+1} \cap Q_{n+1} \subset C_{n} \cap Q_{n}$ and $\epsilon \in(0,1)$, we have

$$
\begin{aligned}
\left\|y_{n}-x_{n}\right\|^{2}+2\left\langle y_{n}-x_{n}, x_{n}-\left(\epsilon z_{1}+(1-\epsilon) z_{2}\right)\right\rangle-\epsilon_{n} \\
=\epsilon\left(\left\|y_{n}-x_{n}\right\|^{2}+2\left\langle y_{n}-x_{n}, x_{n}-z_{1}\right\rangle-\epsilon_{n}\right) \\
\quad+(1-\epsilon)\left(\left\|y_{n}-x_{n}\right\|^{2}+2\left\langle y_{n}-x_{n}, x_{n}-z_{2}\right\rangle-\epsilon_{n}\right) \leq 0,
\end{aligned}
$$

for all $n \in \mathbb{N}$, and we have

$$
\left\langle x_{n}-\left(\epsilon z_{1}+(1-\epsilon) z_{2}\right), x_{1}-x_{n}\right\rangle=\epsilon\left\langle x_{n}-z_{1}, x_{1}-x_{n}\right\rangle+(1-\epsilon)\left\langle x_{n}-z_{2}, x_{1}-x_{n}\right\rangle \geq 0,
$$

for all $n \in \mathbb{N}$. Since $C_{1} \cap Q_{1}$ is convex, and by putting $n=1$ in (3.9), (3.10), and (3.11), we have $C_{2} \cap Q_{2}$ is convex. Suppose that $x_{k}$ is given and $C_{k} \cap Q_{k}$ is convex for some $k \geq 2$. It follows by putting $n=k$ in (3.9), (3.10), and (3.11) that $C_{k+1} \cap Q_{k+1}$ is convex. Therefore, by 
mathematical induction, we have $C_{n} \cap Q_{n}$ is convex for all $n \geq 2$, that is, $C_{n} \cap Q_{n}$ is convex for all $n \in \mathbb{N}$. Hence, we obtain that $C_{n} \cap Q_{n}$ is closed and convex for all $n \in \mathbb{N}$.

Next, we prove that $\Omega \subset C_{n} \cap Q_{n}$ for all $n \in \mathbb{N}$. It is obvious that $p \in \Omega \subset C=C_{1} \cap Q_{1}$. Therefore, by (3.1) and (3.8), we have $p \in C_{2}$, and note that $p \in C=Q_{2}$, and so $p \in C_{2} \cap Q_{2}$. Hence, we have $\Omega \subset C_{2} \cap Q_{2}$. Since $C_{2} \cap Q_{2}$ is a nonempty closed convex subset of $C$, there exists a unique element $x_{2} \in C_{2} \cap Q_{2}$ such that $x_{2}=P_{C_{2} \cap Q_{2}}\left(x_{1}\right)$. Suppose that $x_{k} \in C_{k} \cap Q_{k}$ is given such that $x_{k}=P_{C_{k} \cap Q_{k}}\left(x_{1}\right)$, and $p \in \Omega \subset C_{k} \cap Q_{k}$ for some $k \geq 2$. Therefore, by (3.1) and (3.8), we have $p \in C_{k+1}$. Since $x_{k}=P_{C_{k} \cap Q_{k}}\left(x_{1}\right)$, therefore, by Lemma 2.2, we have

$$
\left\langle x_{k}-z, x_{1}-x_{k}\right\rangle \geq 0
$$

for all $z \in C_{k} \cap Q_{k}$. Thus, by (3.1), we have $p \in Q_{k+1}$, and so $p \in C_{k+1} \cap Q_{k+1}$. Hence, we have $\Omega \subset C_{k+1} \cap Q_{k+1}$. Since $C_{k+1} \cap Q_{k+1}$ is a nonempty closed convex subset of $C$, there exists a unique element $x_{k+1} \in C_{k+1} \cap Q_{k+1}$ such that $x_{k+1}=P_{C_{k+1} \cap Q_{k+1}}\left(x_{1}\right)$. Therefore, by mathematical induction, we obtain $\Omega \subset C_{n} \cap Q_{n}$ for all $n \geq 2$, and so $\Omega \subset C_{n} \cap Q_{n}$ for all $n \in \mathbb{N}$, and we can define $x_{n+1}=P_{C_{n+1} \cap Q_{n+1}}\left(x_{1}\right)$ for all $n \in \mathbb{N}$. Hence, we obtain that the iteration (3.1) is well defined.

Next, we prove that $\left\{x_{n}\right\}$ is bounded. Since $x_{n}=P_{C_{n} \cap Q_{n}}\left(x_{1}\right)$ for all $n \in \mathbb{N}$, we have

$$
\left\|x_{n}-x_{1}\right\| \leq\left\|z-x_{1}\right\|
$$

for all $z \in C_{n} \cap Q_{n}$. It follows by $p \in \Omega \subset C_{n} \cap Q_{n}$ that $\left\|x_{n}-x_{1}\right\| \leq\left\|p-x_{1}\right\|$ for all $n \in \mathbb{N}$. This implies that $\left\{x_{n}\right\}$ is bounded, and so are $\left\{y_{n}\right\},\left\{z_{n}\right\}$, and $\left\{u_{n}\right\}$.

Next, we prove that $\left\|x_{n}-x_{n+1}\right\| \rightarrow 0$ and $\left\|u_{n}-u_{n+1}\right\| \rightarrow 0$ as $n \rightarrow \infty$. Since $x_{n+1}=$ $P_{C_{n+1} \cap Q_{n+1}}\left(x_{1}\right) \in C_{n+1} \cap Q_{n+1} \subset C_{n} \cap Q_{n}$, therefore, by (3.13), we have $\left\|x_{n}-x_{1}\right\| \leq\left\|x_{n+1}-x_{1}\right\|$ for all $n \in \mathbb{N}$. This implies that $\left\{\left\|x_{n}-x_{1}\right\|\right\}$ is a bounded nondecreasing sequence; there exists the limit of $\left\|x_{n}-x_{1}\right\|$, that is

$$
\lim _{n \rightarrow \infty}\left\|x_{n}-x_{1}\right\|=m
$$

for some $m \geq 0$. Since $x_{n+1} \in Q_{n+1}$, therefore, by (3.1), we have

$$
\left\langle x_{n}-x_{n+1}, x_{1}-x_{n}\right\rangle \geq 0 .
$$

It follows by (3.15) that

$$
\begin{aligned}
\left\|x_{n}-x_{n+1}\right\|^{2}= & \left\|\left(x_{n}-x_{1}\right)+\left(x_{1}-x_{n+1}\right)\right\|^{2} \\
= & \left\|x_{n}-x_{1}\right\|^{2}+2\left\langle x_{n}-x_{1}, x_{1}-x_{n}\right\rangle \\
& +2\left\langle x_{n}-x_{1}, x_{n}-x_{n+1}\right\rangle+\left\|x_{n+1}-x_{1}\right\|^{2} \\
\leq & \left\|x_{n+1}-x_{1}\right\|^{2}-\left\|x_{n}-x_{1}\right\|^{2} .
\end{aligned}
$$


Journal of Applied Mathematics

Therefore, by (3.14), we obtain

$$
\left\|x_{n}-x_{n+1}\right\| \longrightarrow 0 \text { as } n \longrightarrow \infty
$$

Indeed, from (3.1) we have

$$
\begin{gathered}
\Phi\left(u_{n}, y\right)+\varphi(y)-\varphi\left(u_{n}\right)+\frac{1}{r_{n}}\left\langle y-u_{n}, u_{n}-x_{n}\right\rangle \geq 0, \quad \forall y \in C, \\
\Phi\left(u_{n+1}, y\right)+\varphi(y)-\varphi\left(u_{n+1}\right)+\frac{1}{r_{n+1}}\left\langle y-u_{n+1}, u_{n+1}-x_{n+1}\right\rangle \geq 0, \quad \forall y \in C ;
\end{gathered}
$$

substituting $y=u_{n+1}$ into (3.18) and $y=u_{n}$ into (3.19), we have

$$
\begin{gathered}
\Phi\left(u_{n}, u_{n+1}\right)+\varphi\left(u_{n+1}\right)-\varphi\left(u_{n}\right)+\frac{1}{r_{n}}\left\langle u_{n+1}-u_{n}, u_{n}-x_{n}\right\rangle \geq 0, \\
\Phi\left(u_{n+1}, u_{n}\right)+\varphi\left(u_{n}\right)-\varphi\left(u_{n+1}\right)+\frac{1}{r_{n+1}}\left\langle u_{n}-u_{n+1}, u_{n+1}-x_{n+1}\right\rangle \geq 0 .
\end{gathered}
$$

Therefore, by the condition (A2), we get

$$
\begin{aligned}
0 \leq & \Phi\left(u_{n}, u_{n+1}\right)+\Phi\left(u_{n+1}, u_{n}\right) \\
& +\left\langle u_{n+1}-u_{n}, \frac{u_{n}-x_{n}}{r_{n}}-\frac{u_{n+1}-x_{n+1}}{r_{n+1}}\right\rangle \\
\leq & \left\langle u_{n+1}-u_{n}, \frac{u_{n}-x_{n}}{r_{n}}-\frac{u_{n+1}-x_{n+1}}{r_{n+1}}\right\rangle .
\end{aligned}
$$

It follows that

$$
\begin{aligned}
0 \leq & \left\langle u_{n+1}-u_{n},\left(u_{n}-u_{n+1}\right)+\left(u_{n+1}-x_{n}\right)-\frac{r_{n}}{r_{n+1}}\left(u_{n+1}-x_{n+1}\right)\right\rangle \\
= & \left\langle u_{n+1}-u_{n}, u_{n}-u_{n+1}\right\rangle \\
& +\left\langle u_{n+1}-u_{n},\left(u_{n+1}-x_{n+1}\right)+\left(x_{n+1}-x_{n}\right)-\frac{r_{n}}{r_{n+1}}\left(u_{n+1}-x_{n+1}\right)\right\rangle .
\end{aligned}
$$

Thus, we have

$$
\begin{aligned}
\left\|u_{n+1}-u_{n}\right\|^{2} & \leq\left\langle u_{n+1}-u_{n},\left(x_{n+1}-x_{n}\right)+\left(1-\frac{r_{n}}{r_{n+1}}\right)\left(u_{n+1}-x_{n+1}\right)\right\rangle \\
& \leq\left\|u_{n+1}-u_{n}\right\|\left(\left\|x_{n+1}-x_{n}\right\|+\left|1-\frac{r_{n}}{r_{n+1}}\right|\left\|u_{n+1}-x_{n+1}\right\|\right) .
\end{aligned}
$$


It follows by the condition (C2) that

$$
\begin{aligned}
\left\|u_{n+1}-u_{n}\right\| & \leq\left\|x_{n+1}-x_{n}\right\|+\frac{\left|r_{n+1}-r_{n}\right|}{r_{n+1}}\left\|u_{n+1}-x_{n+1}\right\| \\
& \leq\left\|x_{n+1}-x_{n}\right\|+\left(\frac{M}{r}\right)\left|r_{n+1}-r_{n}\right|
\end{aligned}
$$

where $M=\sup _{n \geq 1}\left\|u_{n}-x_{n}\right\|<\infty$. Therefore, by the condition (C3) and (3.17), we obtain

$$
\left\|u_{n}-u_{n+1}\right\| \longrightarrow 0 \text { as } n \longrightarrow \infty
$$

Next, we prove that $\left\|T^{n} u_{n}-u_{n}\right\| \rightarrow 0$ and $\left\|T u_{n}-u_{n}\right\| \rightarrow 0$ as $n \rightarrow \infty$. Since $x_{n+1} \in C_{n+1}$, by (3.1), we have

$$
\begin{aligned}
\left\|y_{n}-x_{n+1}\right\|^{2} \leq & \left\|x_{n}-x_{n+1}\right\|^{2}+\alpha_{n} \theta_{n} \\
& +\alpha_{n} \beta_{n}\left(\beta_{n} q_{n}+\beta_{n}^{2} L^{2}+\beta_{n}-1\right)\left\|T^{n} u_{n}-u_{n}\right\|^{2},
\end{aligned}
$$

it follows by the condition (C1) that

$$
\begin{aligned}
a^{2}\left(1-b q_{n}-b^{2} L^{2}-b\right)\left\|T^{n} u_{n}-u_{n}\right\|^{2} \\
\quad \leq \alpha_{n} \beta_{n}\left(1-\beta_{n} q_{n}-\beta_{n}^{2} L^{2}-\beta_{n}\right)\left\|T^{n} u_{n}-u_{n}\right\|^{2} \\
\quad \leq\left\|x_{n}-x_{n+1}\right\|^{2}+\alpha_{n} \theta_{n}-\left\|y_{n}-x_{n+1}\right\|^{2} \\
\leq\left\|x_{n}-x_{n+1}\right\|^{2}+b \theta_{n} .
\end{aligned}
$$

Since $\lim _{n \rightarrow \infty} q_{n}=1$ and the condition (C1), we have $\lim _{n \rightarrow \infty}\left(1-b q_{n}-b^{2} L^{2}-b\right)=1-2 b-b^{2} L^{2}>$ 0 . Therefore, from (3.27) by (3.17) and $\lim _{n \rightarrow \infty} \theta_{n}=0$, we obtain

$$
\left\|T^{n} u_{n}-u_{n}\right\| \longrightarrow 0 \text { as } n \longrightarrow \infty
$$

By the uniformly $L$-Lipschitzian of $T$, we have

$$
\begin{aligned}
\left\|u_{n}-T u_{n}\right\| \leq & \left\|u_{n}-u_{n+1}\right\|+\left\|u_{n+1}-T^{n+1} u_{n+1}\right\|+\left\|T^{n+1} u_{n+1}-T^{n+1} u_{n}\right\| \\
& +\left\|T^{n+1} u_{n}-T u_{n}\right\| \\
\leq & (1+L)\left\|u_{n}-u_{n+1}\right\|+\left\|u_{n+1}-T^{n+1} u_{n+1}\right\|+L\left\|T^{n} u_{n}-u_{n}\right\| .
\end{aligned}
$$

Therefore, by (3.25) and (3.28), we obtain

$$
\left\|u_{n}-T u_{n}\right\| \longrightarrow 0 \text { as } n \longrightarrow \infty \text {. }
$$


Journal of Applied Mathematics

Next, we prove that $\left\|y_{n}-x_{n}\right\| \rightarrow 0,\left\|u_{n}-z_{n}\right\| \rightarrow 0$ and $\left\|u_{n}-x_{n}\right\| \rightarrow 0$ as $n \rightarrow \infty$. From (3.26), by the condition (C1), we have

$$
\left\|y_{n}-x_{n+1}\right\|^{2} \leq\left\|x_{n}-x_{n+1}\right\|^{2}+b \theta_{n}+b^{2}\left(b q_{n}+b^{2} L^{2}+b-1\right)\left\|T^{n} u_{n}-u_{n}\right\|^{2}
$$

it follows that

$$
\begin{aligned}
\left\|y_{n}-x_{n}\right\|^{2}= & \left\|\left(y_{n}-x_{n+1}\right)+\left(x_{n+1}-x_{n}\right)\right\|^{2} \\
= & \left\|y_{n}-x_{n+1}\right\|^{2}+2\left\langle y_{n}-x_{n+1}, x_{n+1}-x_{n}\right\rangle+\left\|x_{n+1}-x_{n}\right\|^{2} \\
\leq & \left\|y_{n}-x_{n+1}\right\|^{2}+2\left\|y_{n}-x_{n+1}\right\|\left\|x_{n+1}-x_{n}\right\|+\left\|x_{n+1}-x_{n}\right\|^{2} \\
\leq & 2\left\|x_{n+1}-x_{n}\right\|\left(\left\|x_{n+1}-x_{n}\right\|+\left\|y_{n}-x_{n+1}\right\|\right)+b \theta_{n} \\
& -b^{2}\left(1-b q_{n}-b^{2} L^{2}-b\right)\left\|T^{n} u_{n}-u_{n}\right\|^{2} .
\end{aligned}
$$

Therefore, by (3.17), $\lim _{n \rightarrow \infty} \theta_{n}=0$, and $\lim _{n \rightarrow \infty}\left(1-b q_{n}-b^{2} L^{2}-b\right)=1-2 b-b^{2} L^{2}>0$, we obtain

$$
\left\|y_{n}-x_{n}\right\| \longrightarrow 0 \text { as } n \longrightarrow \infty
$$

From (3.1), we have $\left\|u_{n}-z_{n}\right\|=\beta_{n}\left\|u_{n}-T^{n} u_{n}\right\|$; therefore, by (3.28), we obtain

$$
\left\|u_{n}-z_{n}\right\| \longrightarrow 0 \text { as } n \longrightarrow \infty
$$

By (3.2), (3.3), and the firmly nonexpansiveness of $S_{r_{n}}$, we have

$$
\begin{aligned}
\left\|u_{n}-p\right\|^{2} & \leq\left\langle S_{r_{n}} x_{n}-S_{r_{n}} p, x_{n}-p\right\rangle=\left\langle u_{n}-p, x_{n}-p\right\rangle \\
& =\frac{1}{2}\left(\left\|u_{n}-p\right\|^{2}+\left\|x_{n}-p\right\|^{2}-\left\|u_{n}-x_{n}\right\|^{2}\right),
\end{aligned}
$$

it follows that

$$
\left\|u_{n}-p\right\|^{2} \leq\left\|x_{n}-p\right\|^{2}-\left\|u_{n}-x_{n}\right\|^{2}
$$

Therefore, from (3.8), we have

$$
\begin{aligned}
\left\|y_{n}-p\right\|^{2} \leq & \left\|u_{n}-p\right\|^{2}+\alpha_{n} \theta_{n} \\
& +\alpha_{n} \beta_{n}\left(\beta_{n} q_{n}+\beta_{n}^{2} L^{2}+\beta_{n}-1\right)\left\|T^{n} u_{n}-u_{n}\right\|^{2} \\
\leq & \left\|x_{n}-p\right\|^{2}-\left\|u_{n}-x_{n}\right\|^{2}+\alpha_{n} \theta_{n} \\
& +\alpha_{n} \beta_{n}\left(\beta_{n} q_{n}+\beta_{n}^{2} L^{2}+\beta_{n}-1\right)\left\|T^{n} u_{n}-u_{n}\right\|^{2} ;
\end{aligned}
$$


it follows by the condition (C1) that

$$
\begin{aligned}
\left\|u_{n}-x_{n}\right\|^{2} \leq & \left\|x_{n}-p\right\|^{2}-\left\|y_{n}-p\right\|^{2}+\alpha_{n} \theta_{n} \\
& +\alpha_{n} \beta_{n}\left(\beta_{n} q_{n}+\beta_{n}^{2} L^{2}+\beta_{n}-1\right)\left\|T^{n} u_{n}-u_{n}\right\|^{2} \\
\leq & \left\|x_{n}-y_{n}\right\|\left(\left\|x_{n}-p\right\|+\left\|y_{n}-p\right\|\right)+b \theta_{n} \\
& -b^{2}\left(1-b q_{n}-b^{2} L^{2}-b\right)\left\|T^{n} u_{n}-u_{n}\right\|^{2} .
\end{aligned}
$$

Therefore, by (3.33), $\lim _{n \rightarrow \infty} \theta_{n}=0$, and $\lim _{n \rightarrow \infty}\left(1-b q_{n}-b^{2} L^{2}-b\right)=1-2 b-b^{2} L^{2}>0$, we obtain

$$
\left\|u_{n}-x_{n}\right\| \longrightarrow 0 \text { as } n \longrightarrow \infty
$$

Since $\left\{u_{n}\right\}$ is bounded, there exists a subsequence $\left\{u_{n_{i}}\right\}$ of $\left\{u_{n}\right\}$ which converges weakly to $\bar{w}$. Next, we prove that $\bar{w} \in \Omega$. From $u_{n_{i}}-\bar{w}$ and $\left\|u_{n_{i}}-T u_{n_{i}}\right\| \rightarrow 0$ as $i \rightarrow \infty$ by (3.30), therefore, by Lemma 2.5, we obtain $\bar{w} \in F(T)$. From (3.1), we have

$$
0 \leq \Phi\left(u_{n}, y\right)+\varphi(y)-\varphi\left(u_{n}\right)+\frac{1}{r_{n}}\left\langle y-u_{n}, u_{n}-x_{n}\right\rangle, \quad \forall y \in C
$$

it follows by the condition (A2) that

$$
\begin{aligned}
\Phi\left(y, u_{n}\right) & \leq \Phi\left(y, u_{n}\right)+\Phi\left(u_{n}, y\right)+\varphi(y)-\varphi\left(u_{n}\right)+\frac{1}{r_{n}}\left\langle y-u_{n}, u_{n}-x_{n}\right\rangle, \quad \forall y \in C \\
& \leq \varphi(y)-\varphi\left(u_{n}\right)+\frac{1}{r_{n}}\left\langle y-u_{n}, u_{n}-x_{n}\right\rangle, \quad \forall y \in C .
\end{aligned}
$$

Hence,

$$
\varphi(y)-\varphi\left(u_{n_{i}}\right)+\left\langle y-u_{n_{i}}, \frac{u_{n_{i}}-x_{n_{i}}}{r_{n_{i}}}\right\rangle \geq \Phi\left(y, u_{n_{i}}\right), \quad \forall y \in C
$$

Therefore, from (3.39) and by $u_{n_{i}} \rightarrow \bar{w}$ as $i \rightarrow \infty$, we obtain

$$
\Phi(y, \bar{w})+\varphi(\bar{w})-\varphi(y) \leq 0, \quad \forall y \in C
$$

For a constant $t$ with $0<t<1$ and $y \in C$, let $y_{t}=t y+(1-t) \bar{w}$. Since $y, \bar{w} \in C$, thus, $y_{t} \in C$. So, from (3.43), we have

$$
\Phi\left(y_{t}, \bar{w}\right)+\varphi(\bar{w})-\varphi\left(y_{t}\right) \leq 0
$$


By (3.44), the conditions (A1) and (A4), and the convexity of $\varphi$, we have

$$
\begin{aligned}
0 & =\Phi\left(y_{t}, y_{t}\right)+\varphi\left(y_{t}\right)-\varphi\left(y_{t}\right) \\
& \leq\left(t \Phi\left(y_{t}, y\right)+(1-t) \Phi\left(y_{t}, \bar{w}\right)\right)+(t \varphi(y)+(1-t) \varphi(\bar{w}))-\varphi\left(y_{t}\right) \\
& =t\left(\Phi\left(y_{t}, y\right)+\varphi(y)-\varphi\left(y_{t}\right)\right)+(1-t)\left(\Phi\left(y_{t}, \bar{w}\right)+\varphi(\bar{w})-\varphi\left(y_{t}\right)\right) \\
& \leq t\left(\Phi\left(y_{t}, y\right)+\varphi(y)-\varphi\left(y_{t}\right)\right)
\end{aligned}
$$

it follows that

$$
\Phi\left(y_{t}, y\right)+\varphi(y)-\varphi\left(y_{t}\right) \geq 0
$$

Therefore, by the condition (A3) and the weakly lower semicontinuity of $\varphi$, we have $\Phi(\bar{w}, y)+$ $\varphi(y)-\varphi(\bar{w}) \geq 0$ as $t \rightarrow 0$ for all $y \in C$, and hence, we obtain $\bar{w} \in \operatorname{MEP}(\Phi, \varphi)$, and so $\bar{w} \in \Omega$.

Since $\Omega$ is a nonempty closed convex subset of $C$, there exists a unique $w \in \Omega$ such that $w=P_{\Omega}\left(x_{1}\right)$. Next, we prove that $x_{n} \rightarrow w$ as $n \rightarrow \infty$. Since $w=P_{\Omega}\left(x_{1}\right)$, we have $\left\|x_{1}-w\right\| \leq\left\|x_{1}-z\right\|$ for all $z \in \Omega$; it follows that

$$
\left\|x_{1}-w\right\| \leq\left\|x_{1}-\bar{w}\right\|
$$

Since $w \in \Omega \subset C_{n} \cap Q_{n}$, therefore, by (3.13), we have

$$
\left\|x_{1}-x_{n}\right\| \leq\left\|x_{1}-w\right\|
$$

Since $\left\|x_{n_{i}}-u_{n_{i}}\right\| \rightarrow 0$ by (3.39) and $u_{n_{i}} \rightarrow \bar{w}$, we have $x_{n_{i}} \rightarrow \bar{w}$ as $i \rightarrow \infty$. Therefore, by (3.47), (3.48) and the weak lower semicontinuity of norm, we have

$$
\left\|x_{1}-w\right\| \leq\left\|x_{1}-\bar{w}\right\| \leq \liminf _{i \rightarrow \infty}\left\|x_{1}-x_{n_{i}}\right\| \leq \limsup _{i \rightarrow \infty}\left\|x_{1}-x_{n_{i}}\right\| \leq\left\|x_{1}-w\right\| .
$$

It follows that

$$
\left\|x_{1}-w\right\|=\lim _{i \rightarrow \infty}\left\|x_{1}-x_{n_{i}}\right\|=\left\|x_{1}-\bar{w}\right\|
$$

Since $x_{n_{i}} \rightarrow \bar{w}$ as $i \rightarrow \infty$, therefore, we have

$$
\left(x_{1}-x_{n_{i}}\right) \rightarrow\left(x_{1}-\bar{w}\right) \quad \text { as } i \longrightarrow \infty
$$

Hence, from (3.50), (3.51), Kadec-Klee property, and the uniqueness of $w=P_{\Omega}\left(x_{1}\right)$, we obtain

$$
x_{n_{i}} \longrightarrow \bar{w}=w \quad \text { as } i \longrightarrow \infty
$$

It follows that $\left\{x_{n}\right\}$ converges strongly to $w$ and so are $\left\{y_{n}\right\},\left\{z_{n}\right\}$, and $\left\{u_{n}\right\}$. This completes the proof. 
Remark 3.2. The iteration (3.1) is the difference with the iterative scheme of Qin et al. [7] as follows.

(1) The sequence $\left\{x_{n}\right\}$ is a projection sequence of $x_{1}$ onto $C_{n} \cap Q_{n}$ for all $n \in \mathbb{N}$ such that

$$
C_{1} \cap Q_{1} \supset C_{2} \cap Q_{2} \supset \cdots \supset C_{n} \cap Q_{n} \supset \cdots \supset \Omega
$$

(2) A solving of a common element of the set of fixed point for an asymptotically pseudocontractive mapping in the intermediate sense and the set of solutions of the mixed equilibrium problems by iteration is obtained.

We define the condition (B3) as the condition (B1) such that $\varphi=0$. If $\varphi=0$, then Theorem 3.1 is reduced immediately to the following result.

Corollary 3.3. Let $C$ be a nonempty closed convex subset of a real Hilbert space $H$, and let $\Phi$ a bifunction from $C \times C$ into $\mathbb{R}$ satisfying the conditions (A1)-(A5) with either (B2) or (B3) holds. Let $T: C \rightarrow C$ be a uniformly L-Lipschitzian such that $L>0$ and asymptotically pseudocontractive mapping in the intermediate sense defined as in (1.13) with the sequences $\left\{k_{n}\right\} \subset[1, \infty)$ and $\left\{\tau_{n}\right\} \subset$ $[0, \infty)$ such that $\lim _{n \rightarrow \infty} k_{n}=1$ and $\lim _{n \rightarrow \infty} \tau_{n}=0$. Let $q_{n}=2 k_{n}-1$ for all $n \in \mathbb{N}$. Assume that $\Omega:=F(T) \cap \mathrm{EP}(\Phi)$ be a nonempty bounded subset of $C$. For $x_{1}=x \in C$ chosen arbitrarily, suppose that $\left\{x_{n}\right\},\left\{y_{n}\right\},\left\{z_{n}\right\}$, and $\left\{u_{n}\right\}$ are generated iteratively by

$$
\begin{gathered}
u_{n} \in C \text { such that } \Phi\left(u_{n}, y\right)+\frac{1}{r_{n}}\left\langle y-u_{n}, u_{n}-x_{n}\right\rangle \geq 0, \quad \forall y \in C, \\
z_{n}=\left(1-\beta_{n}\right) u_{n}+\beta_{n} T^{n} u_{n}, \\
y_{n}=\left(1-\alpha_{n}\right) u_{n}+\alpha_{n} T^{n} z_{n}, \\
C_{n+1}=\left\{z \in C_{n} \cap Q_{n}:\left\|y_{n}-z\right\|^{2} \leq\left\|x_{n}-z\right\|^{2}+\alpha_{n} \theta_{n}\right. \\
\left.+\alpha_{n} \beta_{n}\left(\beta_{n} q_{n}+\beta_{n}^{2} L^{2}+\beta_{n}-1\right)\left\|T^{n} u_{n}-u_{n}\right\|^{2}\right\}, \\
Q_{n+1}=\left\{z \in C_{n} \cap Q_{n}:\left\langle x_{n}-z, x_{1}-x_{n}\right\rangle \geq 0\right\}, \\
C_{1}=Q_{1}=C, \\
x_{n+1}=P_{C_{n+1} \cap Q_{n+1}}\left(x_{1}\right), \quad \forall n \in \mathbb{N},
\end{gathered}
$$

where $\theta_{n}=\left(q_{n}\left[1+\beta_{n}\left(q_{n}-1\right)\right]-1\right) \cdot \Delta_{n}^{2}+2\left(\beta_{n} q_{n}+1\right) \tau_{n}$ and $\Delta_{n}=\sup \left\{\left\|x_{n}-z\right\|: z \in \Omega\right\}<\infty$ satisfying the following conditions:

(C1) $\left\{\alpha_{n}\right\},\left\{\beta_{n}\right\} \subset(0,1)$ such that $a \leq \alpha_{n} \leq \beta_{n} \leq b$ for some $a>0$ and $b \in\left(0, L^{-2}\left(\sqrt{1+L^{2}}-\right.\right.$ 1));

(C2) $\left\{r_{n}\right\} \subset[r, \infty)$ for some $r>0$;

(C3) $\sum_{n=1}^{\infty}\left|r_{n+1}-r_{n}\right|<\infty$.

Then the sequences $\left\{x_{n}\right\},\left\{y_{n}\right\},\left\{z_{n}\right\}$, and $\left\{u_{n}\right\}$ converge strongly to $w=P_{\Omega}\left(x_{1}\right)$.

If $\Phi=0$, then Corollary 3.3 is reduced immediately to the following result. 
Corollary 3.4. Let $C$ be a nonempty closed convex subset of a real Hilbert space $H$. Let $T: C \rightarrow C$ be a uniformly L-Lipschitzian such that $L>0$ and asymptotically pseudocontractive mapping in the intermediate sense defined as in (1.13) with the sequences $\left\{k_{n}\right\} \subset[1, \infty)$ and $\left\{\tau_{n}\right\} \subset[0, \infty)$ such that $\lim _{n \rightarrow \infty} k_{n}=1$ and $\lim _{n \rightarrow \infty} \tau_{n}=0$. Let $q_{n}=2 k_{n}-1$ for all $n \in \mathbb{N}$. Assume that $F(T)$ be a nonempty bounded subset of $C$. For $x_{1}=x \in C$ chosen arbitrarily, suppose that $\left\{x_{n}\right\},\left\{y_{n}\right\}$, and $\left\{z_{n}\right\}$ are generated iteratively by

$$
\begin{aligned}
z_{n}= & \left(1-\beta_{n}\right) x_{n}+\beta_{n} T^{n} x_{n}, \\
y_{n}= & \left(1-\alpha_{n}\right) x_{n}+\alpha_{n} T^{n} z_{n}, \\
C_{n+1}= & \left\{z \in C_{n} \cap Q_{n}:\left\|y_{n}-z\right\|^{2} \leq\left\|x_{n}-z\right\|^{2}+\alpha_{n} \theta_{n}\right. \\
& \left.\quad+\alpha_{n} \beta_{n}\left(\beta_{n} q_{n}+\beta_{n}^{2} L^{2}+\beta_{n}-1\right)\left\|T^{n} x_{n}-x_{n}\right\|^{2}\right\}, \\
Q_{n+1}= & \left\{z \in C_{n} \cap Q_{n}:\left\langle x_{n}-z, x_{1}-x_{n}\right\rangle \geq 0\right\}, \\
C_{1}= & Q_{1}=C, \\
x_{n+1}= & P_{C_{n+1} \cap Q_{n+1}}\left(x_{1}\right), \quad \forall n \in \mathbb{N},
\end{aligned}
$$

where $\theta_{n}=\left(q_{n}\left[1+\beta_{n}\left(q_{n}-1\right)\right]-1\right) \cdot \Delta_{n}^{2}+2\left(\beta_{n} q_{n}+1\right) \tau_{n}, \Delta_{n}=\sup \left\{\left\|x_{n}-z\right\|: z \in F(T)\right\}<\infty$ and $\left\{\alpha_{n}\right\},\left\{\beta_{n}\right\} \subset(0,1)$ such that $a \leq \alpha_{n} \leq \beta_{n} \leq b$ for some $a>0$ and $b \in\left(0, L^{-2}\left(\sqrt{1+L^{2}}-1\right)\right)$. Then the sequences $\left\{x_{n}\right\},\left\{y_{n}\right\}$ and $\left\{z_{n}\right\}$ converge strongly to $w=P_{F(T)}\left(x_{1}\right)$.

We introduce the equilibrium problem to the optimization problem:

$$
\min _{x \in C} \zeta(x)
$$

where $C$ is a nonempty closed convex subset of a real Hilbert space $H$ and let $\zeta: C \rightarrow$ $\mathbb{R} \cup\{+\infty\}$ is a proper convex and lower semicontinuous. We denote by $\operatorname{Argmin}(\zeta)$ the set of solution of problem (3.56). We define the condition (B4) as the condition (B3) such that $\Phi: C \times C \rightarrow \mathbb{R}$ is a bifunction defined by $\Phi(x, y)=\zeta(y)-\zeta(x)$ for all $x, y \in C$. Observe that $\mathrm{EP}(\Phi)=\operatorname{Argmin}(\zeta)$. We obtain that Corollary 3.3 is reduced immediately to the following result.

Corollary 3.5. Let $C$ is a nonempty closed convex subset of a real Hilbert space $H$, and $\zeta: C \rightarrow$ $\mathbb{R} \cup\{+\infty\}$ be a proper lower semicontinuous and convex function with either (B2) or (B4) holds. Let $T: C \rightarrow C$ be a uniformly L-Lipschitzian such that $L>0$ and asymptotically pseudocontractive mapping in the intermediate sense defined as in (1.13) with the sequences $\left\{k_{n}\right\} \subset[1, \infty)$ and $\left\{\tau_{n}\right\} \subset$ $[0, \infty)$ such that $\lim _{n \rightarrow \infty} k_{n}=1$ and $\lim _{n \rightarrow \infty} \tau_{n}=0$. Let $q_{n}=2 k_{n}-1$ for all $n \in \mathbb{N}$. Assume that $\Omega:=F(T) \cap \operatorname{Argmin}(\zeta)$ be a nonempty bounded subset of $C$. For $x_{1}=x \in C$ chosen arbitrarily, suppose that $\left\{x_{n}\right\},\left\{y_{n}\right\},\left\{z_{n}\right\}$ and $\left\{u_{n}\right\}$ are generated iteratively by

$$
\begin{gathered}
u_{n} \in C \text { such that } \zeta(y)-\zeta\left(u_{n}\right)+\frac{1}{r_{n}}\left\langle y-u_{n}, u_{n}-x_{n}\right\rangle \geq 0, \quad \forall y \in C, \\
z_{n}=\left(1-\beta_{n}\right) u_{n}+\beta_{n} T^{n} u_{n}
\end{gathered}
$$




$$
\begin{gathered}
y_{n}=\left(1-\alpha_{n}\right) u_{n}+\alpha_{n} T^{n} z_{n}, \\
C_{n+1}=\left\{z \in C_{n} \cap Q_{n}:\left\|y_{n}-z\right\|^{2} \leq\left\|x_{n}-z\right\|^{2}+\alpha_{n} \theta_{n}\right. \\
\left.+\alpha_{n} \beta_{n}\left(\beta_{n} q_{n}+\beta_{n}^{2} L^{2}+\beta_{n}-1\right)\left\|T^{n} u_{n}-u_{n}\right\|^{2}\right\}, \\
Q_{n+1}=\left\{z \in C_{n} \cap Q_{n}:\left\langle x_{n}-z, x_{1}-x_{n}\right\rangle \geq 0\right\}, \\
C_{1}=Q_{1}=C, \\
x_{n+1}=P_{C_{n+1} \cap Q_{n+1}}\left(x_{1}\right), \quad \forall n \in \mathbb{N},
\end{gathered}
$$

where $\theta_{n}=\left(q_{n}\left[1+\beta_{n}\left(q_{n}-1\right)\right]-1\right) \cdot \Delta_{n}^{2}+2\left(\beta_{n} q_{n}+1\right) \tau_{n}$ and $\Delta_{n}=\sup \left\{\left\|x_{n}-z\right\|: z \in \Omega\right\}<\infty$ satisfying the following conditions:

(C1) $\left\{\alpha_{n}\right\},\left\{\beta_{n}\right\} \subset(0,1)$ such that $a \leq \alpha_{n} \leq \beta_{n} \leq b$ for some $a>0$ and $b \in\left(0, L^{-2}\left(\sqrt{1+L^{2}}-\right.\right.$ $1))$;

(C2) $\left\{r_{n}\right\} \subset[r, \infty)$ for some $r>0$;

(C3) $\sum_{n=1}^{\infty}\left|r_{n+1}-r_{n}\right|<\infty$.

Then the sequences $\left\{x_{n}\right\},\left\{y_{n}\right\},\left\{z_{n}\right\}$, and $\left\{u_{n}\right\}$ converge strongly to $w=P_{\Omega}\left(x_{1}\right)$.

\section{References}

[1] E. Blum and W. Oettli, "From optimization and variational inequalities to equilibrium problems," The Mathematics Student, vol. 63, no. 1-4, pp. 123-145, 1994.

[2] P. Hartman and G. Stampacchia, "On some non-linear elliptic differential-functional equations," Acta Mathematica, vol. 115, no. 1, pp. 271-310, 1966.

[3] W. Takahashi, Nonlinear Functional Analysis, Fixed point theory and its applications, Yokohama Publishers, Yokohama, Japan, 2000.

[4] W. R. Mann, "Mean value methods in iteration," Proceedings of the American Mathematical Society, vol. 4, pp. 506-510, 1953.

[5] J. Schu, "Iterative construction of fixed points of asymptotically nonexpansive mappings," Journal of Mathematical Analysis and Applications, vol. 158, no. 2, pp. 407-413, 1991.

[6] J. K. Kim and Y. M. Nam, "Modified Ishikawa iterative sequences with errors for asymptotically setvalued pseudocontractive mappings in Banach spaces," Bulletin of the Korean Mathematical Society, vol. 43, no. 4, pp. 847-860, 2006.

[7] X. Qin, S.-Y. Cho, and J.-K. Kim, "Convergence theorems on asymptotically pseudocontractive mappings in the intermediate sense," Fixed Point Theory and Applications, Article ID 186874, 14 pages, 2010.

[8] F. E. Browder and W. V. Petryshyn, "Construction of fixed points of nonlinear mappings in Hilbert space," Journal of Mathematical Analysis and Applications, vol. 20, pp. 197-228, 1967.

[9] T.-H. Kim and H.-K. Xu, "Strong convergence of modified Mann iterations," Nonlinear Analysis, vol. 61, no. 1-2, pp. 51-60, 2005.

[10] S. Reich, "Weak convergence theorems for nonexpansive mappings in Banach spaces," Journal of Mathematical Analysis and Applications, vol. 67, no. 2, pp. 274-276, 1979.

[11] A. Genel and J. Lindenstrauss, "An example concerning fixed points," Israel Journal of Mathematics, vol. 22, no. 1, pp. 81-86, 1975.

[12] K. Nakajo and W. Takahashi, "Strong convergence theorems for nonexpansive mappings and nonexpansive semigroups," Journal of Mathematical Analysis and Applications, vol. 279, no. 2, pp. 372 $379,2003$. 
[13] S. Ishikawa, "Fixed points by a new iteration method," Proceedings of the American Mathematical Society, vol. 44, no. 1, pp. 147-150, 1974.

[14] H. Zhou, "Demiclosedness principle with applications for asymptotically pseudo-contractions in Hilbert spaces," Nonlinear Analysis, vol. 70, no. 9, pp. 3140-3145, 2009.

[15] W. Takahashi, Introduction to Nonlinear and Convex Analysis, Yokohama Publishers, Yokohama, Japan, 2009.

[16] J.-W. Peng and J.-C. Yao, “Two extragradient methods for generalized mixed equilibrium problems, nonexpansive mappings and monotone mappings," Journal of Computers and Mathematics with Applications, vol. 58, no. 7, pp. 1287-1301, 2009. 


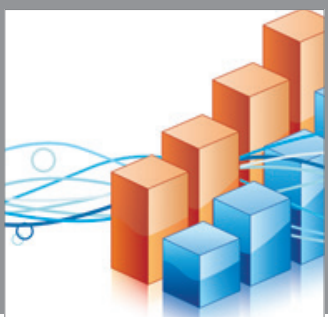

Advances in

Operations Research

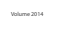

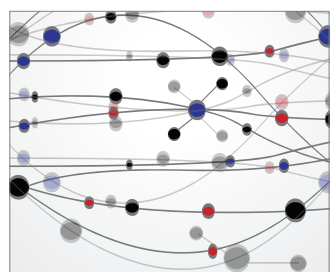

\section{The Scientific} World Journal
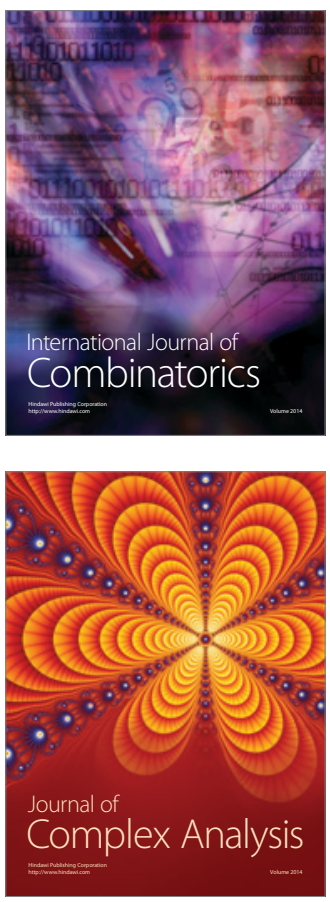

International Journal of

Mathematics and

Mathematical

Sciences
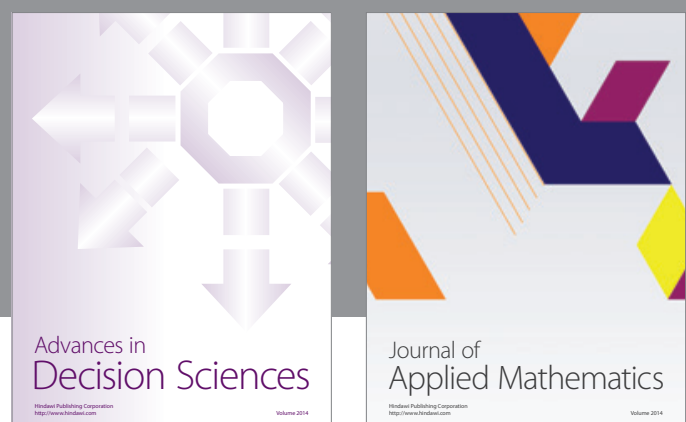

Journal of

Applied Mathematics
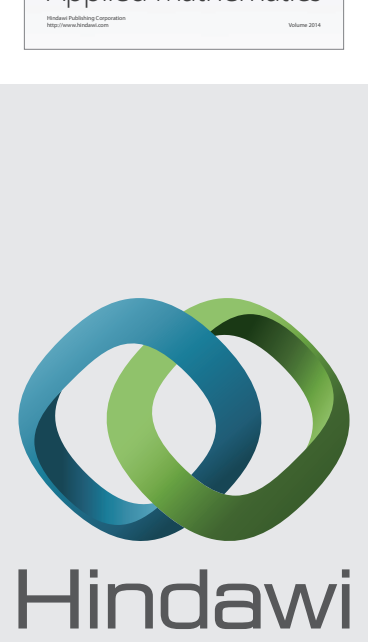

Submit your manuscripts at http://www.hindawi.com
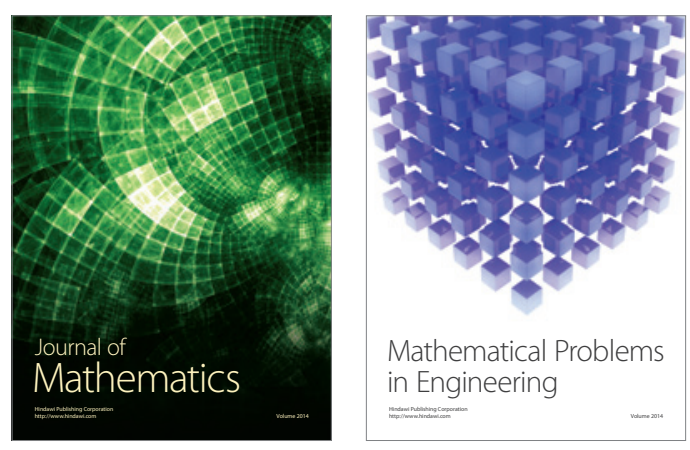

Mathematical Problems in Engineering
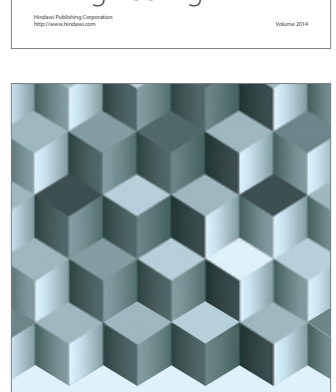

Journal of

Function Spaces
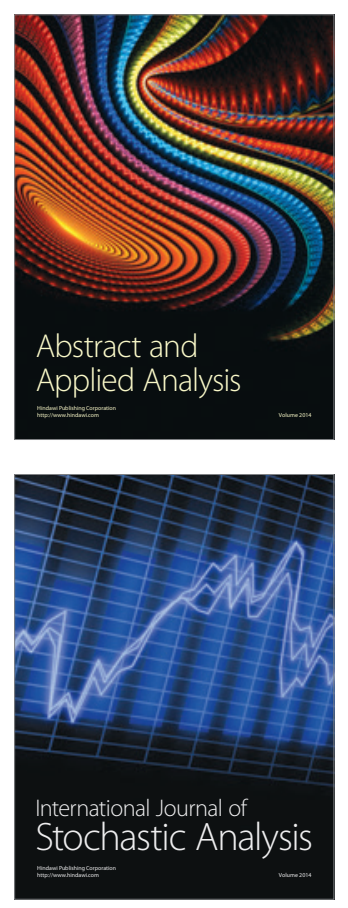

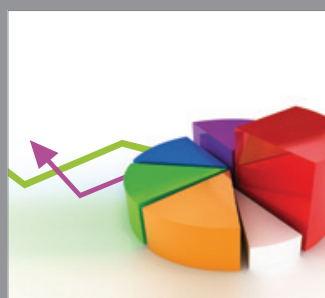

ournal of

Probability and Statistics

Promensencen
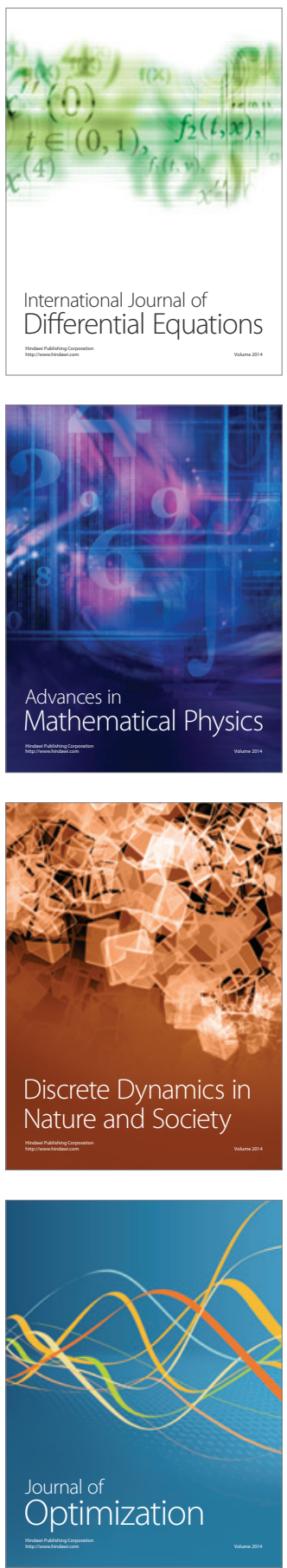